\title{
Assess 'Til We Drop?
}

BY SIMON BOXALL

JUNE IS THE TIME that oceanography undergraduates have the cleanest shoes and tidiest rooms, and have contacted everyone in their mobile phone directories-many for the first time since last year. University professors of oceanography are similarly up to date with these mundane tasks. The reason? Exams and assessments. It only takes three lectures' worth of notes on Intermediate Physical Oceanography for a student to realize how keen Aunt Beryl might be to hear from her nephew, or a small mountain of "Could climate change impact the Gulf Stream?” essays for an academic's thoughts to wander to those sandals that haven't been polished since earlier this morning.

For me, on a train back from London last week, the London Times looked far more appealing than yet another student telling me that the Gulf Stream was created by Stommel. Eminent though Henry was, even he would have had difficulty moving that much seawater. One article in particular grabbed my attention by posing the question: Do we over assess in university courses? It proposed that students today are bombarded with so much assessment that they approach most of their study strategically to ensure that they obtain the top marks, but not necessarily the best learning. It referred

Simon Boxall (srb2@noc.soton.ac.uk) is Associate Fellow, University of Southampton, National Oceanography Centre, Southampton, UK. to research suggesting that 8-10 pieces of assessment during a degree course should be sufficient to fairly place a student on the grading system. Let's face it-once they have been successful in their first jobs, few employers look to the finer points of their degrees, relying more on their performance and output in the work place.

So why do we assess? Assessment, we are continuously told, falls into two "categories"; formative and summative. In the former, the assessment is itself a learning experience that evolves substantive knowledge, develops skills, and helps communication. The latter has limited learning outcomes but tests students on what they have understood (or perhaps just learned in rote fashion). Formative assessment has always to me seemed the best value of my time, but many students want a summary of where they are, regardless of whether they can learn from the experience. As academics, we are under pressure to assess students for their future careers and for our own league tables. Students expect to be assessed, and often the biggest gripe I hear is, "Why is this component of the course not graded?" There is also a perception that without assessment students won't bother doing the work-and this perception comes from both sides of the fence.

At Southampton, we recently decided to limit the number of assessments that count toward a grade in any one course to three-whether practical, essay, or exam. That's great! But with each student taking eight units each year, that represents nearly 100 pieces of assessed work towards the final degree. Worse still, we have 100 students per year in our oceanography or marine biology degree program. That means that we assess 10,000 pieces of work-per year! One has to question how effective feedback can be with these sorts of figures-and whether without that feedback the student learns little and cannot develop.

A $\mathrm{PhD}$ student, taking a more advanced degree, has one piece of assessed work-two if you count a presentation or oral viva as well as the thesis itself. I then cast my mind back to my own degree-yes, universities had been created that long ago. Our final year was the only one that counted, and for five units we had one exam and for three others dissertations, well within the recommendations of the report referenced in the Times article. So what has changed and has it been for the better or the worse? For the early years (one and two) in our school, a high proportion of assessment is at present summative $-70 \%$ of an average first-year course is exam based. In the later years (three and four), it is formativedissertation, presentations, Web pageswith less than $30 \%$ being exam based. The feedback on this formative work is far more useful than that for exams, where technically all students get is their grades, with no formal opportunity to go through their exam papers to see where they went right (or wrong). 
What is of note is that while many students show a gradual improvement in grades as they progress through the university system, a few see a drop.

Often, these are students who come with very good high school grades, where rote learning and exam technique are unfortunately more common than they should be. They have learned the system and can play it well. The move from summative to formative is not an easy one for these students, and while they don't fail, they do slip from the very top of the class. What of other universities around the globe? I did a quick survey of colleagues in the United States, Canada, France, and Australia, and with a few regional variations we all seem to assess extensively and in much the same way-great for consistency, but is it the best option for us or the students?

One of the major pieces of work undergraduates tackle in their final year is a dissertation. Like a $\mathrm{PhD}$ thesis, it brings together skills of academic ability, data processing, communication (many have an oral presentation component as well as the written report), and organization. It shows what the students have learned and gathered in their time at university. It involves working closely with academics and their research teams, and there is often continuous feedback on research outcomes and written work. While one would not dare suggest that an entire degree program be assessed by one dissertation (though it works for a $\mathrm{PhD}$ ), I did conjecture as to what sample

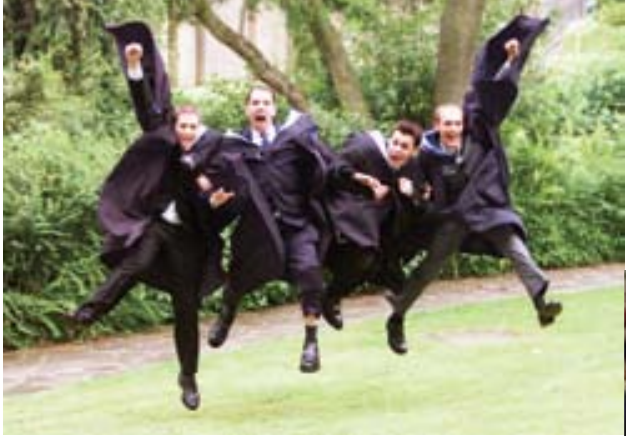

of work is needed to reflect a student's ability and understanding.

In another of those diversionary schemes while confronted with 170 firstyear papers on Introductory Physical

Oceanography, I looked at our past three years of finalists and selected what I considered to be eight representative pieces of work from each. These example works included the dissertation, two fieldwork reports, three exams, and two essays taken from all but the first year. The result: they have done 88 pieces of assessed work more than needed and, equally, we have marked 9,200 extra pieces. The rank order of students changed by no more than three places for any one student; there were two exceptions to this rule, but both were unusual cases. One had problems in his second year (and consequently did better in my new regime), and the other hadn't completed a dissertation (and had done considerably worse). It was also the case that the average marks for each of the years were raised by between $3 \%$ and $5 \%$.

Now, I do hear the argument that some of those 88 excess pieces were formative and thus of benefit to the student, and certainly I'm not suggesting that we provide no feedback for the majority of the work students do. Perhaps it should be our job more to guide rather than to assess and, as with our graduate students, to make our assessments more meaningful and formative.

In conclusion, what are we looking for in our oceanographers of the future and
Left. Assessment leads to student satisfaction and a degree. Below. Assessment takes many forms, including assessed practical sessions.

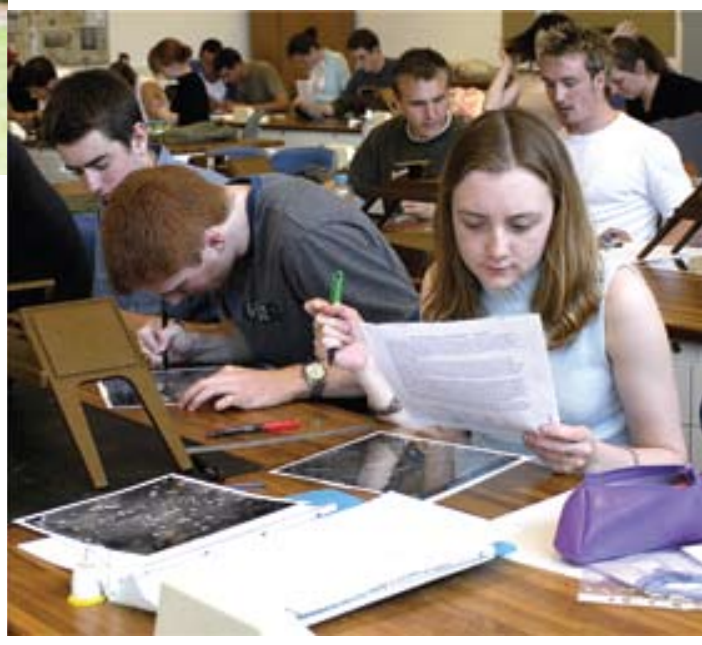

are we assessing them correctly? Most employers want independent thinkers who have developed a raft of transferable skills and know where to find information even if they don't remember everything they have been taught. They want staff who are adaptable and work to very high standards. Most university departments want to produce students of this caliber and to take raw freshmen and turn them into early-stage, able oceanographers, and to see good progress in those students. Most students want to come out of university fit for work and having had an enjoyable and fulfilling time. It is clear that, as the Times stated, we are over assessing our students, and I think many academic departments are aware of that and tackling the issue. But, it will be a brave Dean of Education who reduces assessment volume to $10 \%$ of what it is today in one go. I suspect over the course of the next decade we will see acceptance by students and external quality-control audits of the idea that less assessment is more, and in the end produces well-balanced marine scientists.

The only problem is my sandals will never be as clean again. ⿷匚 